\title{
Study of geometries of active magnetic regenerators for room temperature magnetocaloric refrigeration
}

\author{
Lei, Tian; Engelbrecht, Kurt; Nielsen, Kaspar Kirstein; Veje, Christian T.
}

Published in:

Applied Thermal Engineering

Link to article, DOI:

10.1016/j.applthermaleng.2015.11.113

Publication date:

2017

Document Version

Peer reviewed version

Link back to DTU Orbit

Citation $(A P A)$ :

Lei, T., Engelbrecht, K., Nielsen, K. K., \& Veje, C. T. (2017). Study of geometries of active magnetic regenerators for room temperature magnetocaloric refrigeration. Applied Thermal Engineering, 111, 1232-1243. https://doi.org/10.1016/j.applthermaleng.2015.11.113

\section{General rights}

Copyright and moral rights for the publications made accessible in the public portal are retained by the authors and/or other copyright owners and it is a condition of accessing publications that users recognise and abide by the legal requirements associated with these rights.

- Users may download and print one copy of any publication from the public portal for the purpose of private study or research.

- You may not further distribute the material or use it for any profit-making activity or commercial gain

- You may freely distribute the URL identifying the publication in the public portal 


\title{
Study on Geometries of Active Magnetic Regenerators for Room Temperature Magnetocaloric Refrigeration
}

Tian Lei ${ }^{1}$, Kurt Engelbrecht ${ }^{1}$, Kaspar K. Nielsen ${ }^{1}$, and Christian T. Veje ${ }^{2}$

${ }^{1}$ Department of Energy Conversion and Storage, Technical University of Denmark, Frederiksborgvej 399, DK 4000 Roskilde, Denmark

${ }^{2}$ Mærsk Mc-Kinney Møller Instituttet, University of Southern Denmark, DK 5230 Odense M, Denmark

September 1, 2015

tile@dtu.dk

\begin{abstract}
Room temperature magnetic refrigeration has attracted substantial attentions during the past decades and further promoting the performance of active magnetic regenerators (AMR) is of great interest. Optimizing the regenerator geometry and related operating parameters is a practical and effective way to obtain the desired cooling performance. To investigate how to choose and optimize the AMR geometry, a quantitative study is presented by simulation based on a one-dimensional model. Various correlations for calculating friction factor and heat transfer coefficient are reviewed and chosen for modeling different geometries. Moreover, the synthetic impacts of various parameters on the regenerator efficiency with a constant specific cooing capacity are
\end{abstract}


presented. An analysis based on entropy production minimization reveals how those parameters affect the main losses occurring inside the AMR. In addition, optimum geometry and operating parameters corresponding to the best efficiency for different geometries are presented and compared. The results show that the parallel plate and micro-channel matrices show the highest theoretical efficiency, while the packed screen bed and packed sphere bed are more practical from the applications point of view. Keywords: magnetic refrigeration, active magnetic regeneration, regenerator geometry, heat transfer

\section{Introduction}

Room temperature magnetocaloric refrigeration (MCR) has been developed significantly in recent years and many prototypes with significant cooling capacity have emerged [1, 2, 3]. Okamura et al [4] in 2007 presented a rotary active magnetocaloric refrigerator, which provided $540 \mathrm{~W}$ no-load cooling power and maximum temperature span of $21 \mathrm{~K}$. In 2012, a rotary prototype exhibiting a no-load temperature span of over $25 \mathrm{~K}$ and maximum cooling power of $1010 \mathrm{~W}$ using gadolinium (Gd) spheres was developed by Engelbrecht et al [5]. Arnold et al [6] modified a compact magnetocaloric refrigerator in 2014 and it realized a no-load temperature span of $33 \mathrm{~K}$ using $650 \mathrm{~g}$ of Gd. In 2014, Jacobs et al [7] built a rotary prototype using six layers of LaFeSiH particles, and it produced $3042 \mathrm{~W}$ of cooling power at zero temperature span and $2502 \mathrm{~W}$ over a span from 32 to $44{ }^{\circ} \mathrm{C}$ with coefficient of performance (COP) around 2. However, a clear gap still exists between the requirements of high power density / efficiency and the performances of available MCR systems. To improve the performance, researchers have focused on various techniques, such as developing novel magnetocaloric materials, increasing the maximum applied magnetic field of permanent magnet, reducing the losses by using ingenious designs, and optimizing the regenerator geometry as well as related operating parameters. The last approach is of substantial interest to many machine builders, since it is practical and important to get close to the best performance 
with existing materials and techniques.

The AMR is a porous media made of magnetocaloric materials (MCM), which is the solid refrigerant, and the porous structure allows the heat transfer liquid to flow through the regenerator bed and transfer heat with the solid at the same time. As shown in Figure 1, a typical AMR cycle is comprised of four processes. Starting with the adiabatic magnetization process, the temperature of MCM increases, and then the heat transfer fluid is heated by those solid refrigerants during the cold to hot blow. Due to a temperature difference, the fluid rejects excessive heat to the hot reservoir. The next adiabatic demagnetization process drives a decrease in solid temperature and the hot-to-cold blow makes the fluid reach a lower temperature than the initial state at the cold reservoir. Finally, the fluid absorbs heat from the cold reservoir, which completes the cycle. In each AMR cycle, the fluid is assumed to enter the packed bed with a constant temperature $T_{H}$ at the hot end during the hot-to-cold blow, or $T_{C}$ at the cold end during the cold-to-hot blow. Therefore, the temperature span is $\Delta T=T_{H}-T_{C}$. The heating power, cooling power and the COP are defined as:

$$
\begin{aligned}
Q_{H} & =\int\left|\dot{m}_{f}\right|\left(h_{f, x=0}-h_{f, T_{H}}\right) d t \text { when } \dot{m}_{f}<0 \\
Q_{C} & =\int\left|\dot{m}_{f}\right|\left(h_{f, T_{C}}-h_{f, x=L}\right) d t \text { when } \dot{m}_{f}>0 \\
C O P & =\frac{Q_{C}}{Q_{H}-Q_{C}}
\end{aligned}
$$

where $\dot{m}_{f}$ and $t$ is the mass flow rate and time; $h_{f, x=0}$ and $h_{f, x=L}$ are the specific enthalpies of the fluid flowing out of the hot and cold end; $h_{f, T_{H}}$ and $h_{f, T_{C}}$ are the specific enthalpies of the fluid at $T_{H}$ and $T_{C}$ in each blow period. The two blow processes are synchronized with a periodically varying magnetic field, and the four processes may overlap in timing sequence in a real prototype.

From a thermodynamic view point, the most obvious causes of reduced cooling capacity or efficiency of the AMRs include imperfect heat transfer between the fluid and solid refrigerant, viscous dissipation due to the pump work, axial conduction, and heat loss to 
the ambient. The last issue is not discussed here, while we mainly focus on the other three irreversible mechanisms. Those losses are directly or indirectly related to the aforementioned regenerator geometry and operating parameters. For example, smaller flow channel in a porous regenerator can realize higher heat transfer coefficient, however, it will also lead to an increase in the pressure drop and the viscous dissipation concurrently. Moreover, large power density requires high frequency operation, which may oppositely raise the risk of imperfect heat transfer due to reduced blow time. Important parameters related to the regenerator geometry include the regenerator type, hydraulic diameter, porosity, and aspect ratio. In addition, the frequency, averaged mass flow rate, temperature span, and applied magnetic field are typical operating parameters. Since those parameters interactively affect the regenerator performance, the choice and optimization should be carefully done for achieving desired cooling performance.

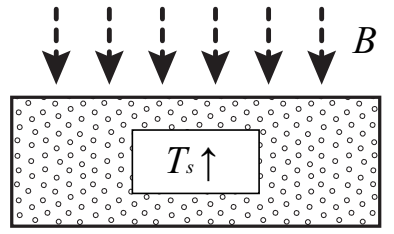

(a) Adiabatic magnetization

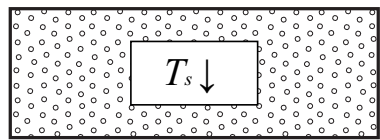

(c) Adiabatic demagnetization

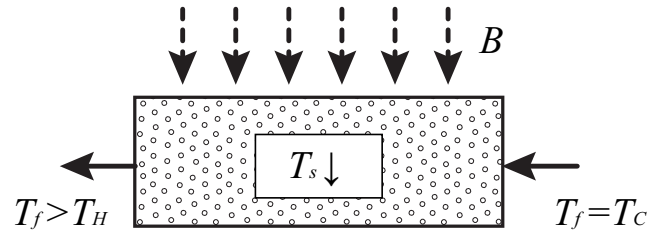

(b) Cold-to-hot blow

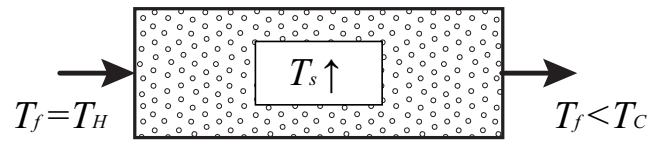

(d) Hot-to-cold blow

Figure 1: Active magnetic regeneration cycle consisted by four processes: (a), adiabatic magnetization; (b), cold-to-hot blow; (c), adiabatic demagnetization; (d), hot-to-cold blow.

In general, good regenerator geometry requires sufficient heat transfer between fluid and porous solid matrix, low pressure drop, and small axial conduction. Among those issues, the imperfect heat transfer and the viscous dissipation are two main loss mechanisms, while the axial conduction should be stressed when dealing with short and bulky regenerators. In various prototypes, which were well reviewed in Ref. [1, 2, 3], the packed particle bed 
and parallel plate matrix were two commonly used geometries. Due to the advantages of easy construction and good heat transfer performance, the packed particle beds were widely implemented. However, the pressure drop over the packed particle beds and the viscous dissipation loss are relatively large, which may cause a reduction in regenerator efficiency. Although the parallel plate matrix has much lower frictional pressure drop compared to the former, high heat transfer coefficient is hard to obtain in experiments due to the limitation of fabricating small channels. The micro-channel matrix for MCR application, which consists of numerous micro channels opened through a monolithic block, has been presented in a few of papers [8, 9].

Radebaugh and Louie in 1985 [10] presented a comparison study on different regenerator geometries for the regenerative refrigerators. For various geometries, the ratios of heat transfer modulus to friction factor $\mathrm{StPr}^{2 / 3} / f_{F}$, where St, $\mathrm{Pr}$, and $f_{F}$ are the Stanton number, Prandtl number, and friction factor respectively, was compared. The Stanton number St is the ratio of the heat transferred into fluid to the thermal capacity of fluid. Their study showed that the parallel plate and micro-channel matrices were preferable concerning a balance between heat transfer and pressure drop. The secondary group included the rod bundle matrix, packed screen bed, and packed sphere bed. The authors also debated that the parallel plate or micro-channel matrices were not suitable for the cryogenic regenerators because of their relatively large longitudinal conduction. In reality, the packed screen bed and packed sphere bed are widely used in regenerative heat engines / refrigerators instead of the parallel plate or micro-channel matrices. In 1984, Barclay and Sarangi [11] compared four different geometries for MCR application by using a simplified model, which included the packed sphere bed, parallel plate matrix, and micro-channel matrix. The study showed optimal characteristic dimension and aspect ratio for different regenerator geometries in three frequencies. More recently, Li et al. [12] in 2008 presented the optimization of the sphere diameter and aspect ratio for AMR using the packed sphere bed by a one-dimensional (1D) model. Vuarnoz and Kawanami in 2012 [13] simulated the AMRs using stacked wire matrix, 
and compared the results with the packed sphere bed. Li et al. in 2012 [14] compared the regenerators with the packed sphere bed and parallel plate matrix by simulation, and the latter showed smaller total entropy production rate and better performance. In 2013, Tušek et al. [15] presented the optimization of AMR with the packed sphere bed and parallel plate matrix in two operating frequencies based on a 1D model.

However, the study on the AMR geometry is insufficient and interesting geometries like packed screen beds are not included. In the following, a general analysis on the regenerator geometries is presented. The correlations for estimating friction factor and heat transfer coefficient of different geometries are reviewed and proper ones are chosen for modeling. By using a one-dimensional model, the synthetic impacts of various parameters on regenerator performance are quantified and analyzed. Moreover, the entropy production rates due to different loss mechanisms inside the AMRs are calculated and compared. Assuming a constant specific cooling power, the maximum COP of regenerators using different geometries and the optimum geometry and operating parameters are compared.

\section{Geometry Comparison}

\subsection{Geometry Characterization}

In this section, five regenerator geometries, which are packed sphere bed, parallel plate matrix, circular micro-channel matrix, rectangular micro-channel matrix and packed screen bed, are discussed and the correlations of the friction factor and heat transfer coefficient are briefly reviewed. The schematic diagrams of the different regenerator geometries are showed in Figure 2, where the dark part represents solid refrigerant and the remaining white space is the flow channel.

Table 1 gives the important dimensions and the expressions of various characterizing parameters for different geometries, which include porosity $\varepsilon$, hydraulic diameter $D_{h}$, and volumetric surface area $a_{s}$. The porosity is the void fraction of the porous regenerator; 
the hydraulic diameter is the ratio of the cross sectional area to the wetted perimeter of the cross-section of a flow channel times four; the volumetric surface area is the amount of surface area per unit volume.

Here we use the "packed sphere bed" instead of the packed particle bed although the regenerator beds are always packed with irregular particles in existing prototypes, since in this study all particles are assumed spherical with the same size. This kind of geometry can be easily constructed by packing small spheres into a regenerator housing. In addition, the porosity is viewed as constant as 0.36 since the sphere diameter is much smaller than the housing diameter [16]. Under this consumption, the sphere diameter is the only dimension parameter that characterizes the packed sphere bed, and the boundary effects are neglected, which means the flow is assumed uniform in the cross section. It is found that the hydraulic diameter of a packed sphere bed is proportional to the sphere diameter $D_{s p}$, and the volumetric surface area has an inverse relationship with $D_{s p}$ [17].

The parallel plate matrix can be built by stacking thin plates with certain spacing from each other, and the main dimensions are plate thickness $H_{p 1}$ and flow channel height $H_{p 2}$. The porosity and volumetric surface area is a function of $H_{p 1}$ and $H_{p 2}$, assuming the plate width is much bigger than the channel size. For the circular micro-channel matrix, the hydraulic diameter is the same as the channel diameter $D_{c}$ and the specific surface area can be calculated from the hydraulic diameter and porosity. The hydraulic diameter of the rectangular micro-channel matrix is related to height and width of the flow channel $H_{r 1}$ and $H_{r 2}$. A square channel with $H_{r 1}=H_{r 2}=H_{r}$, gives $D_{h}=H_{r}$. Woven screens have been used for catalytic reaction for a long time, since they have highly ordered structures, high transfer rates, and moderate flow resistances. Armour [18] in 1968 presented the equations for calculating different parameters by using wire diameter $D_{s c}$ and mesh number per meter $M_{s c}$, as shown in Table 1. Only the packed sphere bed can be characterized by only one parameter, and the other geometries need two variables for full identification. Therefore, in this study we use two parameters, the hydraulic diameter and the porosity, to characterize 
the AMR geometries for reasonable comparison.

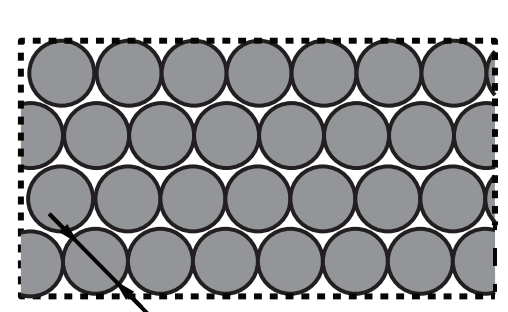

$D_{s p} \backslash$ (a)

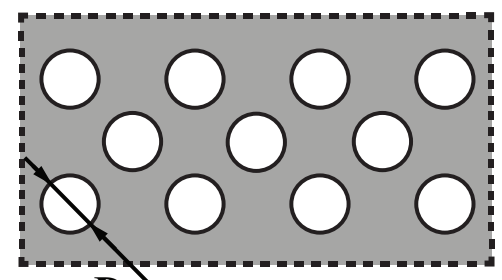

Dc (c)

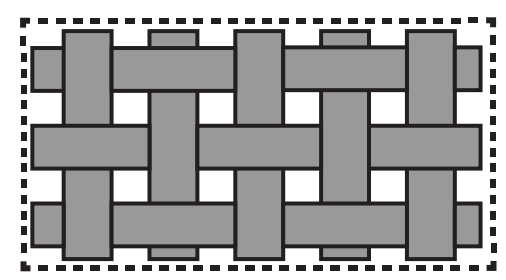

(e-1)

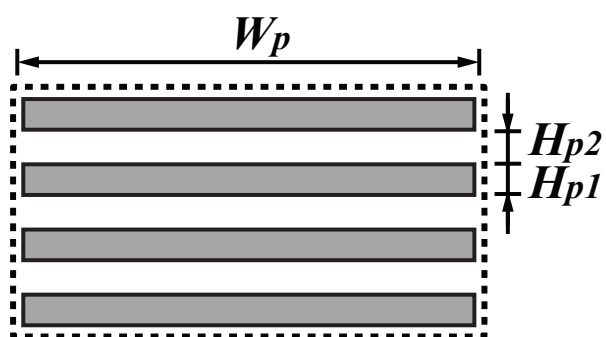

(b)

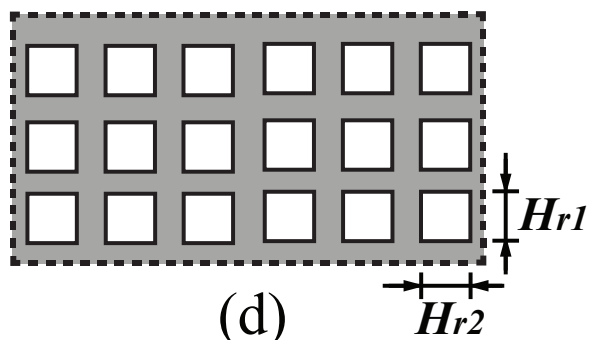

(d)

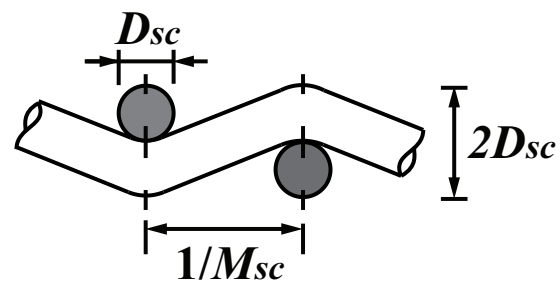

$(\mathrm{e}-2)$

Figure 2: Schematic diagram of different regenerator geometries including (a): packed sphere bed; (b): parallel plate matrix; (c): circular micro-channel matrix; (d): rectangular microchannel matrix; (e-1) and (e-2): top and side views of packed screen bed. Except (e-2), the flow direction is vertical to the schematic diagram. The dark region represents solid refrigerant, i.e., magnetocaloric material, and the rest region represents flow channel.

\subsection{Flow and Heat Transfer Correlations}

As numerous flow and heat transfer correlations for different geometries exists and there are few universally applicable correlations for modeling AMRs, a brief review of correlations is provided in the following. In a typical AMR, metal like Gd is used as the solid refrigerant, while the heat transfer fluid could be aqueous solution with anti-freeze, which has a high 
Table 1: Parameters for characterizing different regenerator geometries

\begin{tabular}{|c|c|c|c|c|}
\hline Geometry & Dimensions & Porosity & Hydraulic diameter & Specific surface area \\
\hline Packed sphere bed & $D_{s p}$ & $\varepsilon=0.36$ & $D_{h}=\frac{2 \varepsilon}{3(1-\varepsilon)} D_{s p}$ & $a_{s}=\frac{4 \varepsilon}{D_{h}}=\frac{6(1-\varepsilon)}{D_{s n}}$ \\
\hline Parallel plate matrix & $H_{p 1}, H_{p 2}$ & $\varepsilon=\frac{H_{p 2}}{H_{p 1}+H_{p 2}}$ & $D_{h}=2 H_{p 2}$ & $a_{s}=\frac{4 \varepsilon}{D_{h}}=\frac{2}{H_{p 1}+H_{p 2}}$ \\
\hline $\begin{array}{l}\text { Circular micro- } \\
\text { channel matrix }\end{array}$ & $D_{c}$ & $\varepsilon$ & $D_{h}=D_{c}$ & $a_{s}=\frac{4 \varepsilon}{D_{h}}=\frac{4 \varepsilon}{D_{c}}$ \\
\hline $\begin{array}{l}\text { Rectangular micro- } \\
\text { channel matrix }\end{array}$ & $H_{r 1}, H_{r 2}$ & $\varepsilon$ & $D_{h}=\frac{2 H_{r 1} H_{r 2}}{H_{r 1}+H_{r 2}}$ & $a_{s}=\frac{4 \varepsilon}{D_{h}}=\frac{2 \varepsilon\left(H_{r 1}+H_{r 2}\right)}{H_{r 1} H_{r 2}}$ \\
\hline Packed screen bed & $M_{s c}, D_{s c}$ & $\begin{array}{l}\varepsilon= \\
1-\frac{\pi M_{s c}^{2} D_{s c}^{2} \sqrt{D_{s c}^{2}+\left(\frac{1}{M_{s c}}-D_{s c}\right)^{2}}}{8 D_{s c}}\end{array}$ & $D_{h}=\frac{4 \varepsilon}{a_{s}}$ & $\begin{array}{l}a_{s}= \\
\frac{2 \pi M_{s c}^{2} D_{s c} \sqrt{D_{s c}^{2}+\left(\frac{1}{M_{s c}}-D_{s c}\right)^{2}}}{2 D_{s c}}\end{array}$ \\
\hline
\end{tabular}

Prandtl number around 5 - 7. Low Reynolds number $(<100)$ flow is predicted as the typical operating condition [19], which is considered during correlation choosing.

The Ergun equation [20] is generally used to calculate the friction factor throughout the packed sphere bed, and the expression includes both viscous and kinetic effects as shown in Table 2, More correlations [21, 22, 23] are compared with the Ergun equation, and it turns out the latter presents a good estimation. Wakao et al [24] in 1979 presented an expression for estimating the Nusselt number for the packed sphere bed. Engelbrecht [25] considered the internal temperature gradient inside solid, and further correlated Wakaos correlation with the Biot number Bi, which is used in this study. The friction factor for the laminar flow through the parallel plates was presented as $f_{F}=24 /$ Re [26], and a similar expression can be found in Ref. [27]. Different correlations for the heat transfer coefficient of the parallel plates were presented in Ref. [27, 28, 29]. Among those, Nickolay and Martin [28] presented a correlation of overall Nusselt number and it gave a good estimation compared with the others. Nielsen et al. [30] analyzed that the Biot number for the parallel plate matrix is much less than 1, which means the heat transfer inside the plate is faster than that across the boundary layer. Therefore, the correlation is not further modified here.

The Poiseuille law and its modified form [31, 32, 33] are generally used to calculate the friction factor for laminar flow through the micro-channel matrix. Comparing Ref. [34, 27, 32, 35] shows that Hausen's correlation [34] is the best for calculating the heat transfer 
coefficient of the circular channel, and the one presented by Kays and London [29] is used for the rectangular channel. Armour and Cannon [18] developed a flow friction correlation applicable to the flow through the most types of woven metal screens with different porosities. It gave the best estimation in contrast to Ref. [36, 37, 38]. Park et al [39] presented a heat transfer correlation based on experiments and it is chosen by comparing with other references [40, 41, 42.

The details of correlation comparison will not be presented in this paper to avoid tedious enumeration. Only chosen correlations for different geometries are presented and compared. Figures $3 \mathrm{a}$ and $3 \mathrm{~b}$ show the friction factor $f_{F}$ and Nusselt number $\mathrm{Nu}$ as a function of Reynolds number $\operatorname{Re}_{h}$ for different geometries, when the porosity is 0.36 and the hydraulic diameter is $0.20 \mathrm{~mm}$. Here the friction factor, Nusselt number, and Reynolds number based on the hydraulic diameter and the superficial velocity $v_{s}$ are:

$$
\begin{aligned}
f_{F} & =\frac{d P}{d x} \frac{2 D_{h}}{\rho_{f} v_{s}^{2}} \\
\mathrm{Nu} & =\frac{h_{f} D_{h}}{k_{f}} \\
\operatorname{Re}_{h} & =\frac{\rho_{f} v_{s} D_{h}}{\mu_{f}} \\
v_{s} & =\frac{\dot{m}_{f}}{\rho_{f} A_{c}}
\end{aligned}
$$

where $d P / d x, D_{h}, \rho_{f}, v_{s}, h_{f}, k_{f}, \mu_{f}, \dot{m}_{f}$, and $A_{c}$, are pressure drop over unit length, hydraulic diameter, density, superficial velocity, heat transfer coefficient, dynamic viscosity, mass flow rate, and cross sectional area, respectively. In some references, the definitions of those correlations are different, as shown in Table 2, so the transform is done for comparison.

Figure $3 \mathrm{a}$ shows that the packed sphere bed exhibits the largest friction factor, and the second is the packed screen bed, whereas the other three have much lower flow resistance. On the contrary, higher Nusselt number can be observed in the packed sphere bed and packed screen bed than the other three geometries as shown in Figure $3 \mathrm{~b}$, Since higher 
Nusselt number $\mathrm{Nu}$ and lower friction factor $f_{F}$ are desirable, the ratio of Nusselt number to friction factor $\mathrm{Nu} / f_{F}$ (see Figure 3c), is utilized to evaluate the regenerator geometries. The parallel plate matrix gives the highest $\mathrm{Nu} / f_{F}$ in this comparison, and the lowest value is observed in the packed sphere bed. It is found that the circular and rectangular microchannel matrices present almost the same friction factor and Nusselt number, therefore in this study we only present the results of the circular micro-channel matrix and note it as "micro-channel matrix". Since the static and dispersion conduction is relatively small, the related correlations for different geometries are not compared in this study and they can be found in Ref. [21, 38, 43, 44, 45]. 


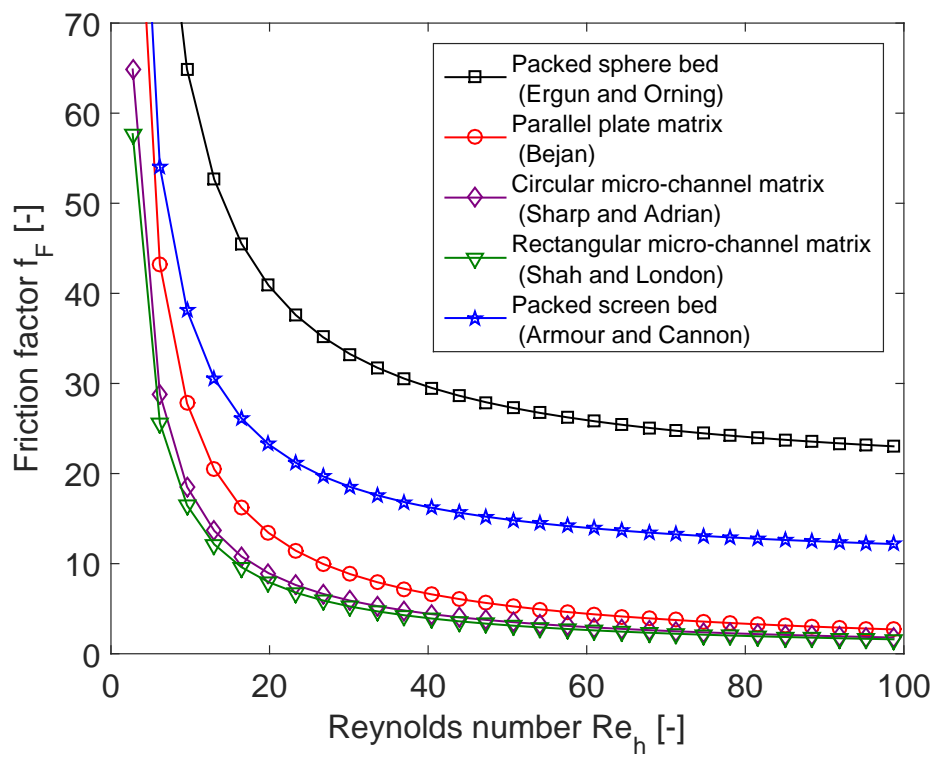

(a) Friction factor $f_{F}$

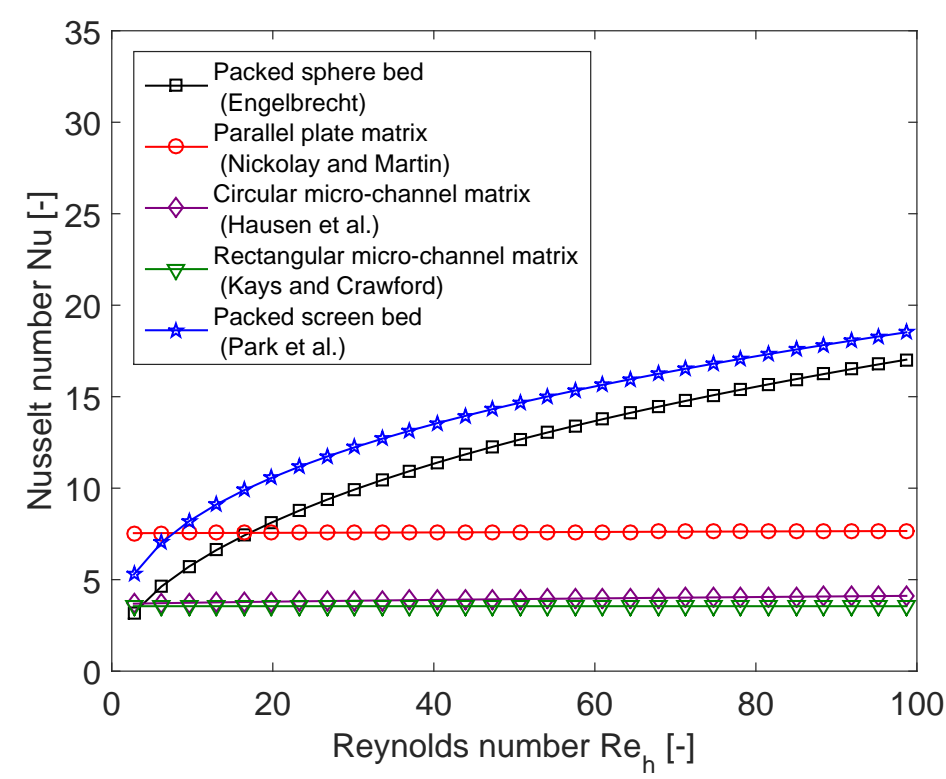

(b) Nusselt number $\mathrm{Nu}$

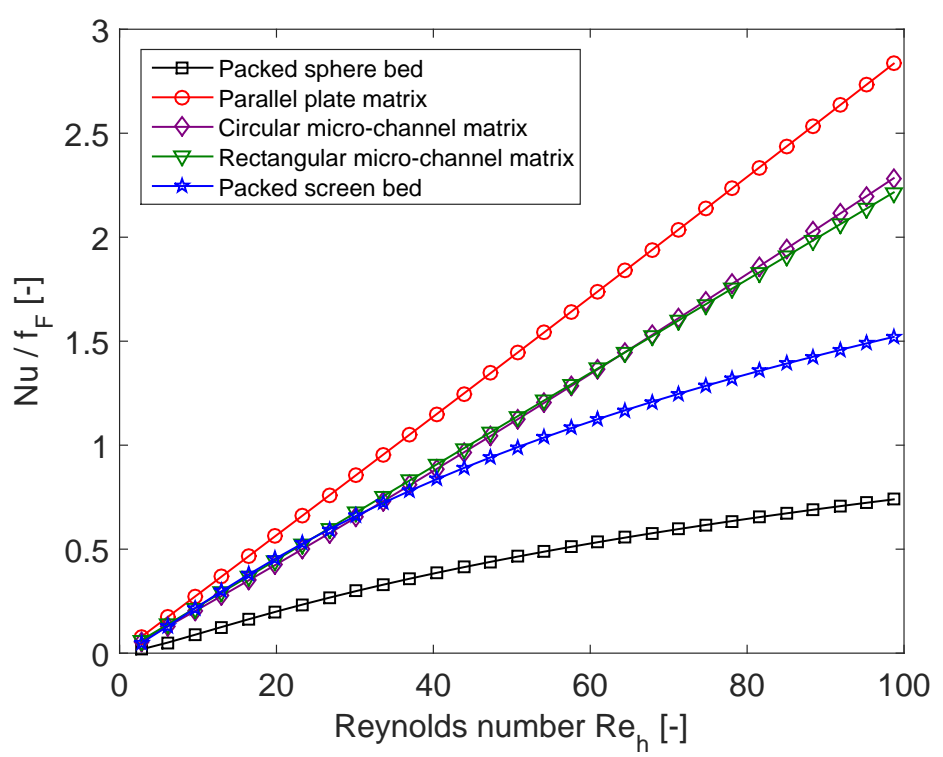

(c) $\mathrm{Nu} / f_{F}$

Figure 3: Nusselt number $\mathrm{Nu}$, friction factor $f_{F}$, and ratio of Nusselt number to friction factor $\mathrm{Nu} / f_{F}$ as a function of Reynolds number $\mathrm{Re}_{h}$ for different geometries when porosity $\varepsilon$ is 0.36 and hydraulic diameter $D_{h}$ is $0.200 \mathrm{~mm}$. 
Table 2: Chosen correlations for different regenerator geometries

\begin{tabular}{|c|c|c|c|c|c|c|}
\hline Reference & Geometry & $\begin{array}{l}\text { Characteristic } \\
\text { dimension length }\end{array}$ & Reynolds number & Friction factor & Pressure drop & Remarks \\
\hline Ergun et al. [20] & $\begin{array}{l}\text { Packed sphere } \\
\text { bed }\end{array}$ & $D_{L}=D_{s p}$ & & & $\begin{array}{l}\frac{d P}{d x}=2 \alpha \frac{(1-\varepsilon)^{2} \mu_{f} v_{s} S_{v}^{2}}{\varepsilon^{3}}+\frac{\beta}{8} \frac{(1-\varepsilon) \rho_{f} v_{s}^{2} S_{v}}{\varepsilon^{3}} \\
\alpha=(\pi / 2)^{2} \approx 2.5, \beta=2.4 \text { and } S_{v}=6 / D_{L}\end{array}$ & $\begin{array}{l}\text { Laminar and turbulent } \\
\text { flow }\end{array}$ \\
\hline Bejan [26] & \begin{tabular}{ll|}
$\begin{array}{l}\text { Parallel } \\
\text { matrix }\end{array}$ & plate \\
\end{tabular} & $D_{L}=2 H_{p 2}$ & $\operatorname{Re}=\frac{\rho_{f}\left(v_{s} / \varepsilon\right) D_{L}}{\mu_{f}}$ & $f_{F}=24 / \operatorname{Re}$ & $\frac{d P}{d x}=4 f_{F}\left[\frac{\rho_{f}\left(v_{s} / \varepsilon\right)^{2}}{2 D_{L}}\right]$ & Laminar flow \\
\hline $\begin{array}{ll}\begin{array}{l}\text { Poiseuille law } \\
\text { (Asadi et al.) }\end{array} & \text { 31] }\end{array}$ & $\begin{array}{l}\text { Circular micro- } \\
\text { channel matrix }\end{array}$ & $D_{L}=D_{c}$ & $\operatorname{Re}=\frac{\rho_{f}\left(v_{s} / \varepsilon\right) D_{L}}{\mu_{f}}$ & $f_{F}=64 / \operatorname{Re}$ & $\frac{d P}{d x}=f_{F}\left[\frac{\rho_{f}\left(v_{s} / \varepsilon\right)^{2}}{2 D_{L}}\right]$ & Laminar flow \\
\hline $\begin{array}{l}\text { Shah and London } \\
\text { 27] }\end{array}$ & $\begin{array}{l}\text { Rectangular } \\
\text { micro-channel } \\
\text { matrix }\end{array}$ & $D_{L}=\frac{2 H_{r 1} H_{r 2}}{H_{r 1}+H_{r 2}}$ & $\operatorname{Re}=\frac{\rho_{f}\left(v_{s} / \varepsilon\right) D_{L}}{\mu_{f}}$ & $\begin{array}{l}f_{F}=24\left(1-1.3553 \alpha+1.9467 \alpha^{2}-\right. \\
\left.1.7012 \alpha^{3}+0.9564 \alpha^{4}-0.2537 \alpha^{5}\right) / \operatorname{Re} \\
\alpha=H_{r 1} / H_{r 2}\end{array}$ & $\frac{d P}{d x}=4 f_{F}\left[\frac{\rho_{f}\left(v_{s} / \varepsilon\right)^{2}}{2 D_{L}}\right]$ & Laminar flow \\
\hline $\begin{array}{l}\text { Armour and Can- } \\
\text { non [18] }\end{array}$ & $\begin{array}{l}\text { Packed screen } \\
\text { bed }\end{array}$ & $D_{L}=\frac{1-M_{s c} D_{s c}}{M_{s c}}$ & $\operatorname{Re}=\frac{\rho_{f} v_{s}}{a_{s}^{2} \mu_{f} D_{L}}$ & $f_{F}=\frac{8.61}{\mathrm{Re}}+0.52$ & $\frac{d P}{d x}=f_{F}\left[\frac{\rho_{f}\left(v_{s} / \varepsilon\right)^{2}}{D_{L}}\right]$ & $\begin{array}{l}0.35<\varepsilon<0.76 \\
0.1<\operatorname{Re}<1000 \\
\end{array}$ \\
\hline Reference & Geometry & $\begin{array}{l}\text { Characteristic } \\
\text { dimension length }\end{array}$ & Reynolds number & Nusselt number & Heat transfer coefficient & Remarks \\
\hline Engelbrecht 25 & $\begin{array}{l}\begin{array}{l}\text { Packed sphere } \\
\text { bed }\end{array} \\
\end{array}$ & $D_{L}=D_{s p}$ & $\operatorname{Re}=\frac{\rho_{f} v_{s} D_{L}}{\mu_{f}}$ & $\mathrm{Nu}=\frac{2+1.1 \mathrm{Pr}^{1 / 3} \mathrm{Re}^{0.6}}{1+\chi \mathrm{Bi} / 5}$ & $h_{f}=\frac{\mathrm{Nu}_{f}}{D_{L}}$ & Laminar flow \\
\hline $\begin{array}{l}\text { Nickolay and Mar- } \\
\text { tin }[28]\end{array}$ & $\begin{array}{l}\text { Parallel plate } \\
\text { matrix }\end{array}$ & $D_{L}=2 H_{p 2}$ & & $\begin{array}{l}\mathrm{Nu}=\left[7.541_{1}^{n}+\left(1.841 \mathrm{Gz}^{1 / 3}\right)^{n}\right]^{(1 / n)} \\
\mathrm{Gz}=\frac{2 v_{s} \rho_{f} \rho_{f} c D_{L}}{k_{f} W_{p} L} \\
n=3.592\end{array}$ & $h_{f}=\frac{\mathrm{Nu} k_{f}}{D_{L}}$ & $\mathrm{Gz}<10^{5}$ \\
\hline Hausen et al. 34 & $\begin{array}{l}\text { Circular micro- } \\
\text { channel matrix }\end{array}$ & $D_{L}=D_{c}$ & $\operatorname{Re}=\frac{\rho_{f}\left(v_{s} / \varepsilon\right) D_{L}}{\mu_{f}}$ & $\begin{array}{l}\mathrm{Nu}=3.657+0.19 C^{0.8} /(1+ \\
\left.0.117 C^{0.467}\right) \\
C=\operatorname{RePr} D_{L} / L\end{array}$ & $h_{f}=\frac{\mathrm{Nu} k_{f}}{D_{L}}$ & $\begin{array}{l}\text { Laminar flow and con- } \\
\text { stant wall temperature }\end{array}$ \\
\hline $\begin{array}{l}\text { Kays and Crawford } \\
{[29]}\end{array}$ & $\begin{array}{l}\text { Rectangular } \\
\text { micro-channel } \\
\text { matrix }\end{array}$ & $D_{L}=\frac{2 H_{r 1} H_{r 2}}{H_{r 1}+H_{r 2}}$ & & $\begin{array}{l}\mathrm{Nu}=8.235\left(1-1.883 / \alpha+3.767 / \alpha^{2}-\right. \\
\left.5.814 / \alpha^{3}+5.361 / \alpha^{4}-2 / \alpha^{5}\right) \\
\alpha=H_{r 1} / H_{r 2}\end{array}$ & $h_{f}=\frac{\mathrm{Nu}_{f}}{D_{L}}$ & Laminar flow \\
\hline Park et al. 39] & $\begin{array}{l}\text { Packed screen } \\
\text { bed }\end{array}$ & $D_{L}=\frac{\varepsilon}{1-\varepsilon} D_{s c}$ & $\operatorname{Re}=\frac{\rho_{f}\left(v_{s} / \varepsilon\right) D_{L}}{\mu_{f}}$ & $\mathrm{Nu}=1.315 \operatorname{Pr}^{1 / 3} \operatorname{Re}^{0.35}\left(\frac{1-\varepsilon}{\varepsilon}\right)^{0.2}$ & $h_{f}=\frac{\mathrm{Nu} k_{f}}{D_{L}}$ & $\begin{array}{l}0.40<\varepsilon<0.84 \\
10<\operatorname{Re}<500\end{array}$ \\
\hline
\end{tabular}




\section{Simulation Model}

To study the AMRs using different geometries, a 1D transient numerical model developed at the Technical University of Denmark [46, 47] is used. The energy equations for the heat transfer liquid and solid refrigerant [25] can be expressed as:

$$
\begin{aligned}
& A_{c} \frac{\partial}{\partial x}\left(k_{\text {disp }} \frac{\partial T_{f}}{\partial x}\right)-\dot{m}_{f} c_{f} \frac{\partial T_{f}}{\partial x}-\frac{N u k_{f}}{D_{h}} a_{s} A_{c}\left(T_{f}-T_{s}\right)+\left|\frac{\partial P}{\partial x} \frac{\dot{m}_{f}}{\rho_{f}}\right|=\rho_{f} A_{c} \varepsilon c_{f} \frac{\partial T_{f}}{\partial t} \\
& \frac{N u k_{f}}{D_{h}} a_{s}\left(T_{f}-T_{s}\right)+A_{c} \frac{\partial}{\partial x}\left(k_{s t a t} \frac{\partial T_{s}}{\partial x}\right)+(1-\varepsilon) \rho_{s} T_{s}\left(\frac{\partial s_{s}}{\partial H}\right)_{T} \frac{\partial H}{\partial t}=\rho_{s}(1-\varepsilon) c_{H} \frac{\partial T_{s}}{\partial t}(9)
\end{aligned}
$$

where $k, T, \rho, c$, and $s$ are the thermal conductivity, temperature, density, specific heat, and specific entropy; $A_{c}, x, t, \dot{m}$, and $H$ are the cross sectional area, axial position, time, mass flow rate and internal magnetic field. The subscripts $f$ and $s$ represent fluid and solid refrigerant, respectively. Table 2 presents the correlations for calculating the pressure drop $\partial P / \partial x$, and the Nusselt number Nu. It should be noted that thermal conductivity due to fluid dispersion $k_{d i s p}$, and static thermal conductivity $k_{\text {stat }}$ are already scaled to fit the cross sectional area. In this numerical model, the mass flow and applied magnetic field are functions of time. The central difference and implicit time schemes are used for discretizing the energy equations in both space and time. By solving the coupled discretized equations, the temperature gradient can be calculated after each time step, given an initial condition. The model outputs the performance indices after reaching the steady state with a tolerance.

Moreover, entropy production minimization is a powerful tool for quantitative analyzing different loss mechanisms inside a thermal system. The second law of thermodynamics requires the entropy production in a natural process positive, and the entropy production minimization can be used to obtain the optimal theoretical performance. This approach can also be used to quantify the irreversibility of various processes in the AMRs. The four main irreversible processes are summarized: (1) imperfect heat transfer process between fluid and solid refrigerant, as well as imperfect heat transfer processes at the hot or cold reservoirs; (2) viscous dissipation through the porous bed due to the flow resistance; (3) axial conduction 
through the bed and conduction due to fluid thermal dispersion; (4) other mechanisms such as irreversibility related to magnetization / demagnetization processes. The last issue is not discussed since it has less relation to this study. The following equations are used to calculate the entropy production rates for different irreversible processes based on the 1D numerical model [12]:

$$
\begin{aligned}
\dot{S}_{p, h t} & =\frac{1}{\tau} \int_{0}^{\tau} \int_{0}^{L} h_{f} a_{s} A_{c} \frac{\left(T_{f}-T_{s}\right)^{2}}{T_{f} T_{s}} d x d t \\
& +\frac{1}{\tau} \int_{0}^{\tau}\left|\dot{m}_{f}\right| c_{f}\left(\ln \frac{T_{C}}{T_{f, x=L}}+\frac{T_{f, x=L}-T_{C}}{T_{C}}+\ln \frac{T_{H}}{T_{f, x=0}}+\frac{T_{f, x=0}-T_{H}}{T_{H}}\right) d t \\
\dot{S}_{p, v d} & =\frac{1}{\tau} \int_{0}^{\tau} \int_{0}^{L} \frac{\left|\dot{m}_{f}\right|}{\rho_{f} T_{f}} \frac{\partial P}{\partial x} d x d t \\
\dot{S}_{p, a c} & =\frac{1}{\tau} \int_{0}^{\tau} \int_{0}^{L}\left[k_{s t a t} A_{c} \frac{1}{T_{s}^{2}}\left(\frac{d T_{s}}{d x}\right)^{2}+k_{d i s p} A_{c} \frac{1}{T_{f}^{2}}\left(\frac{d T_{f}}{d x}\right)^{2}\right] d x d t \\
\dot{S}_{p, t o t} & =\dot{S}_{p, h t}+\dot{S}_{p, v d}+\dot{S}_{p, a c}
\end{aligned}
$$

where $\dot{S}_{p, h t}, \dot{S}_{p, v d}$ and $\dot{S}_{p, a c}$ represent the entropy production rates due to imperfect heat transfer, viscous dissipation, and axial conduction, respectively. It should be noted that there is a numerical error not taken into consideration, which is small and ignorable. By comparing those entropy production rates, we can quantitatively measure the three loss mechanisms.

Table 3 shows the details of the modeling parameters. In the simulation, Gd is used as the refrigerant and water mixture with $20 \% \mathrm{v} / \mathrm{v}$ ethylene glycol as the heat transfer fluid. The magnetocaloric properties of Gd was presented in Ref. [48]. We keep the regenerator volume $V_{r}=L A_{c}$ constant, therefore, the aspect ratio $R_{a}=L / \sqrt{A_{c}}$ can fully describe the regenerator shape. The temperature span is fixed from 280 to $300 \mathrm{~K}$. The profiles of the applied magnetic field and the nominal mass flow rate are showed in Figure 4, while the averaged mass flow rate varies in cases and it is always optimized to obtain the desired specific cooling power. In this way, the frequency becomes the only operating parameter to be optimized. The optimization objectives usually include the specific cooling power, which 
is the cooling power generated using $1 \mathrm{~kg}$ MCM, and COP. However, optimizing both at the same time may make the discussion ambiguous. Therefore, we focus on maximizing COP for obtaining constant specific cooling power.

Table 3: Main modeling parameters

\begin{tabular}{ll}
\hline \hline Parameter & Value \\
\hline Maximum applied magnetic field $B$ & $1.2 \mathrm{~T}$ \\
Regenerator volume $V$ & $22.5 \mathrm{~cm}^{3}$ \\
Aspect ratio $R_{a}$ & $0.1-10$ \\
Frequency $f$ & $0.3-10 \mathrm{~Hz}$ \\
Regenerator number $N_{r}$ & 20 \\
Temperature span $\Delta T$ & $280-300 \mathrm{~K}$ \\
& Packed sphere bed \\
Regenerator geometry & Parallel plate matrix \\
& Micro-channel matrix \\
Hydraulic diameter $D_{h}$ & Packed screen bed \\
Porosity $\varepsilon$ & $0.05-0.20$ mm \\
Heat transfer fluid & $0.36,0.50$, and 0.64 \\
MCM & Aqueous solution with 20\% v/v \\
MCM thermal conductivity $k_{s}$ & ethylene glycol \\
MCM density $\rho_{s}$ & Gadolinium \\
\hline \hline
\end{tabular}




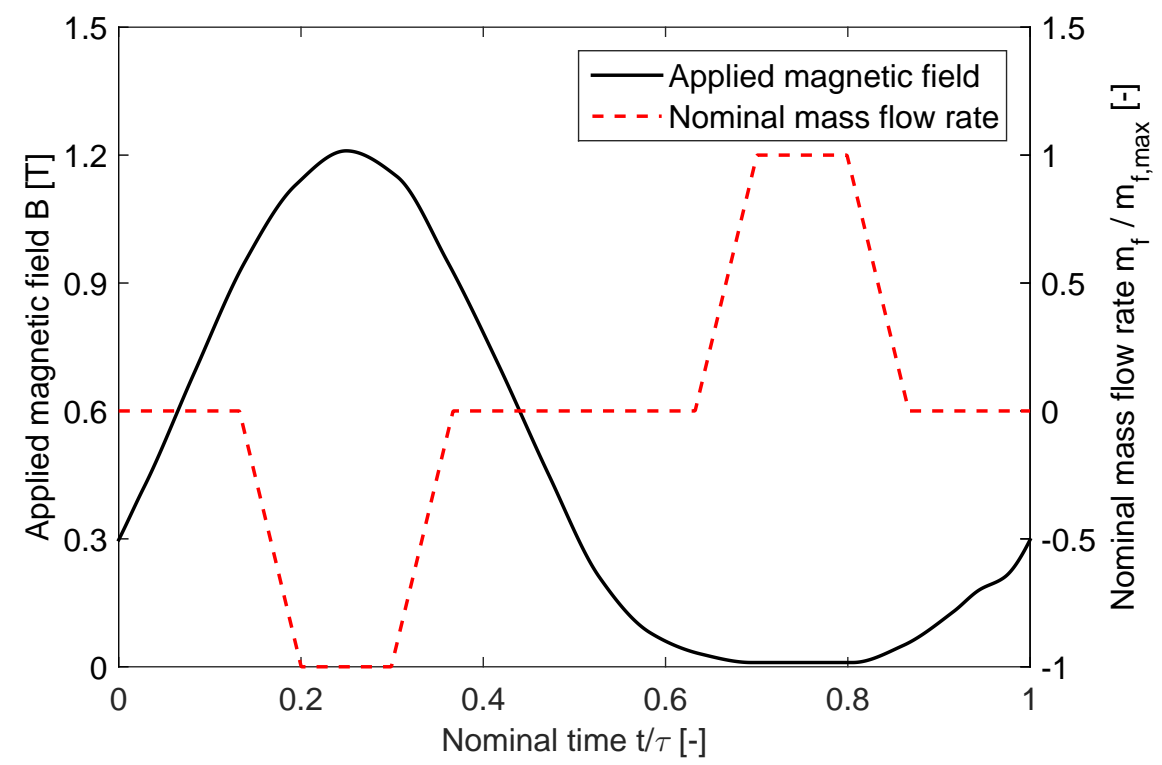

Figure 4: Applied magnetic field $B$ and nominal mass flow rate $\dot{m}_{f} / \dot{m}_{f, \max }$ as a function of nominal time $t / \tau$.

\section{Results and Discussion}

The performances of AMR using four different geometries are presented and discussed in this section. For a reasonable comparison, a desired specific cooling capacity of $100 \mathrm{~W} / \mathrm{kg}$ of regenerator material is assumed and the corresponding COPs are presented below.

\subsection{Packed Sphere Bed}

Figure 5 shows how COP of regenerators using packed sphere bed varies with the frequency $f$ and the aspect ratio $R_{a}$. Four subgraphs represent different hydraulic diameters from 0.05 to $0.20 \mathrm{~mm}$, which are corresponding to the sphere diameters from 0.14 to $0.57 \mathrm{~mm}$. For each case, the frequency ranges from 0.3 to $10 \mathrm{~Hz}$, and the aspect ratio from 0.1 to 10 . In total, about 1800 simulations were done to present the synthetic impacts of those three variables. In general, not only the maximum COP, but also optimum frequency and aspect ratio varies with the hydraulic diameter in Figure $5 \mathrm{a}-5 \mathrm{~d}$,

For the packed sphere bed with a hydraulic diameter of $0.05 \mathrm{~mm}$, the maximum COP 


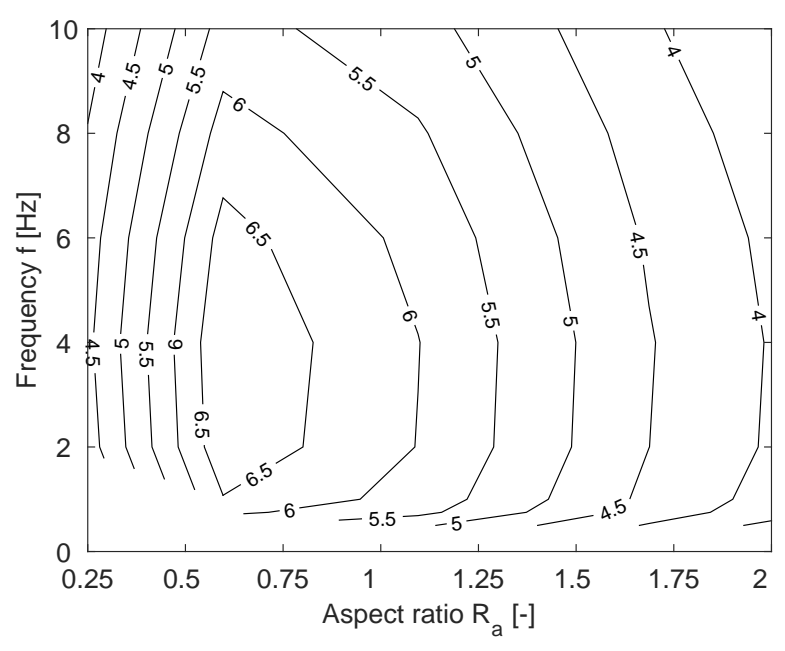

(a) $D_{h}=0.050 \mathrm{~mm}$

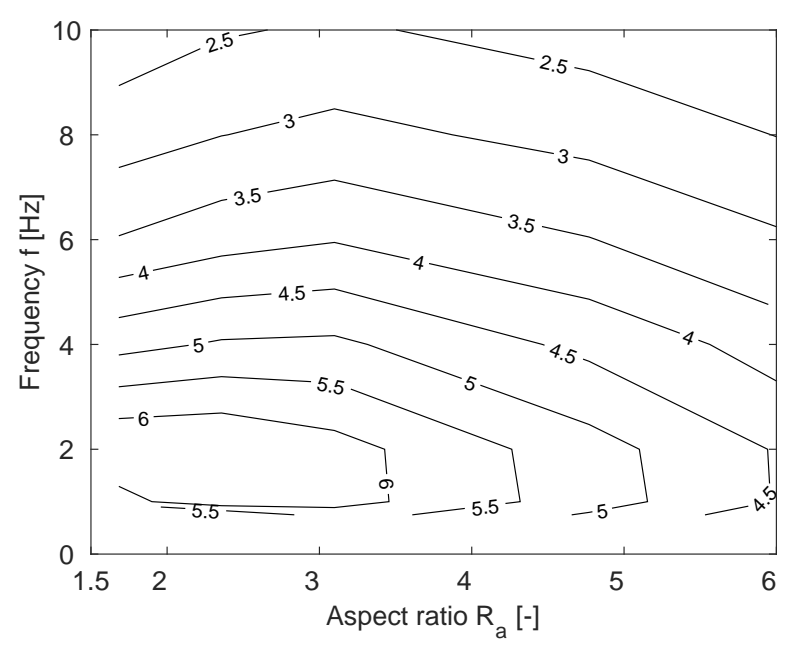

(c) $D_{h}=0.150 \mathrm{~mm}$

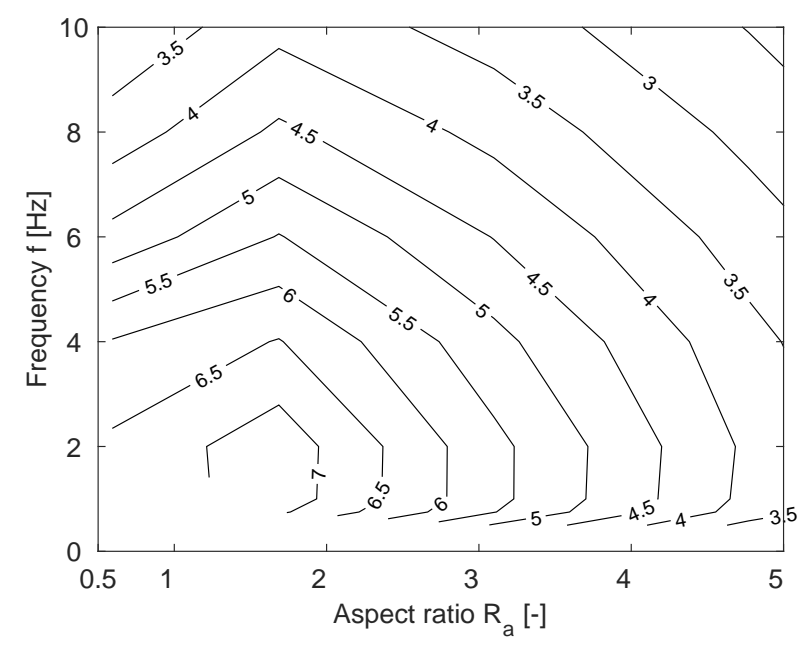

(b) $D_{h}=0.100 \mathrm{~mm}$

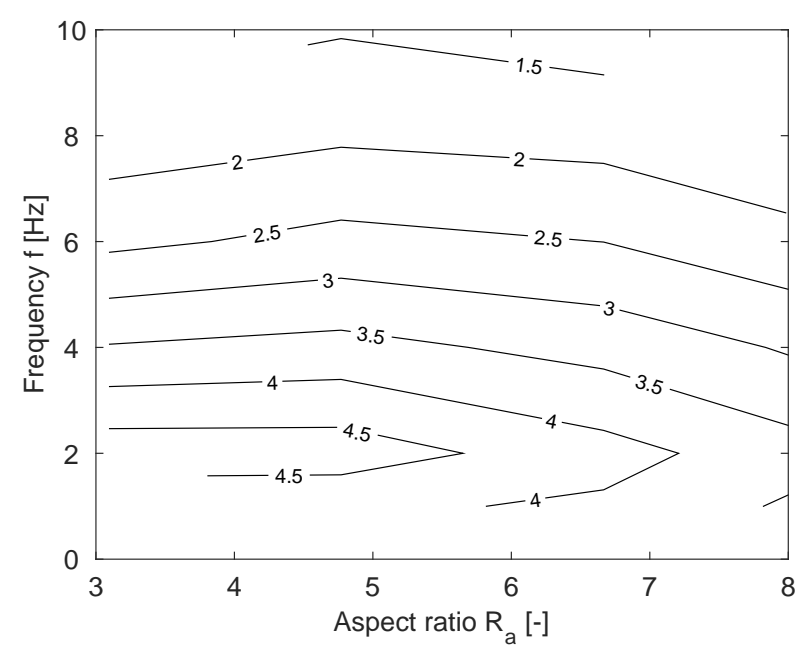

(d) $D_{h}=0.200 \mathrm{~mm}$

Figure 5: COP as a function of frequency $f$ and aspect ratio $R_{a}$ for regenerators using packed sphere bed 
is around 6.9 when the frequency is $3.7 \mathrm{~Hz}$ and the aspect ratio is 0.7 as shown in Figure 5a. Too large or small frequency and aspect ratio can lead to a decrease in COP. The spindle shaped contour reveals that COP changes significantly with the aspect ratio, in contrast it is less sensitive to the frequency. Figure $5 \mathrm{~b}-5 \mathrm{~d}$ shows that the maximum COP becomes 7.2, 6.5, and 4.8 when the hydraulic diameter are $0.10,0.15$, and $0.20 \mathrm{~mm}$, respectively. Simultaneously the optimum frequency shifts to lower and the optimum aspect ratio becomes larger. In the case of a small hydraulic diameter, the pressure drop per unit length is relatively high; therefore a small aspect ratio is necessary in order to prevent the viscous dissipation from dominating. On the other hand, larger hydraulic diameter allows longer regenerator, which in turn increases the risk of imperfect heat transfer. As a result, a relatively low frequency is desired in order to increase the heat transfer time and number of transfer units (NTU), defined as the ratio of the amount of heat transferred between solid and fluid to the thermal mass of the fluid moved. When the hydraulic diameter is larger than or equal to $0.15 \mathrm{~mm}$, the COP becomes more sensitive to frequency instead of aspect ratio, which are displayed in Figure $5 \mathrm{c}$ and $5 \mathrm{~d}$.

Figure 6 summarizes the maximum COP and shows how optimum frequency and aspect ratio shift with the hydraulic diameter, by extracting the information from Figure 5a - 5d, The largest COP is 7.6 when the hydraulic diameter, frequency, and aspect ratio are 0.075 $\mathrm{mm}, 2.3 \mathrm{~Hz}$, and 1.0, respectively.

Figure 7 a shows the total entropy production rates $\dot{S}_{p, t o t}$ as a function of frequency and aspect ratio, which has a reversed pattern compared with the results of COP in Figure 5b. The minimum total production rate is found when the frequency is around $2.0 \mathrm{~Hz}$ and the aspect ratio is 1.7, which fits the position of the maximum COP. As seen in Figure 7b, the entropy production rates due to imperfect heat transfer is strongly related to the frequency rather than the aspect ratio, which may lies in the decreased heat transfer time in one blow. In contrast, $\dot{S}_{p, v d}$ is more sensitive to the aspect ratio than the frequency, which is reflected by the equations for calculating the pressure drop through the bed. Since the 


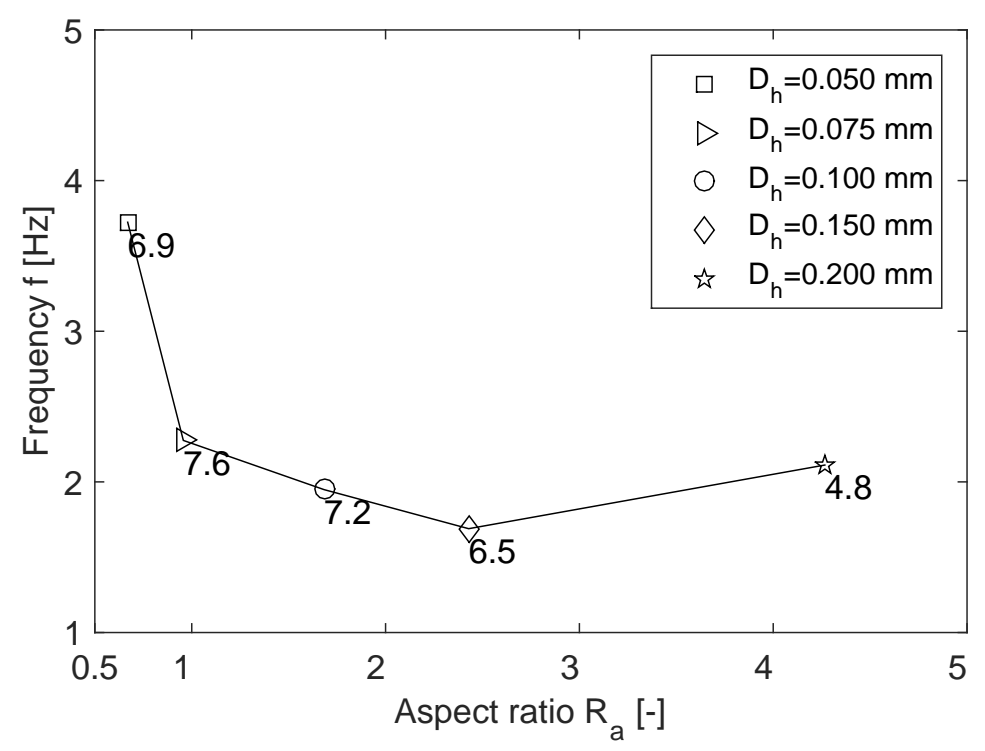

Figure 6: Optimal frequency $f$ and aspect ratio $R_{a}$ for regenerators using packed sphere bed with different hydraulic diameter $D_{h}$

axial conduction loss increases when the cross sectional area becomes larger and the length shorter, $\dot{S}_{p, a c}$ increases significantly with decreasing aspect ratio, however the frequency does not affect $\dot{S}_{p, a c}$ much. In most cases, the entropy production rates representing imperfect heat transfer and viscous dissipation contribute most to the total entropy production rate, whereas the entropy production rate due to axial conduction becomes significant when the aspect ratio is smaller than 1.0. At the point of minimum total entropy production rate, the viscous dissipation contributes the most, and the second is imperfect heat transfer, while the last is axial conduction. 


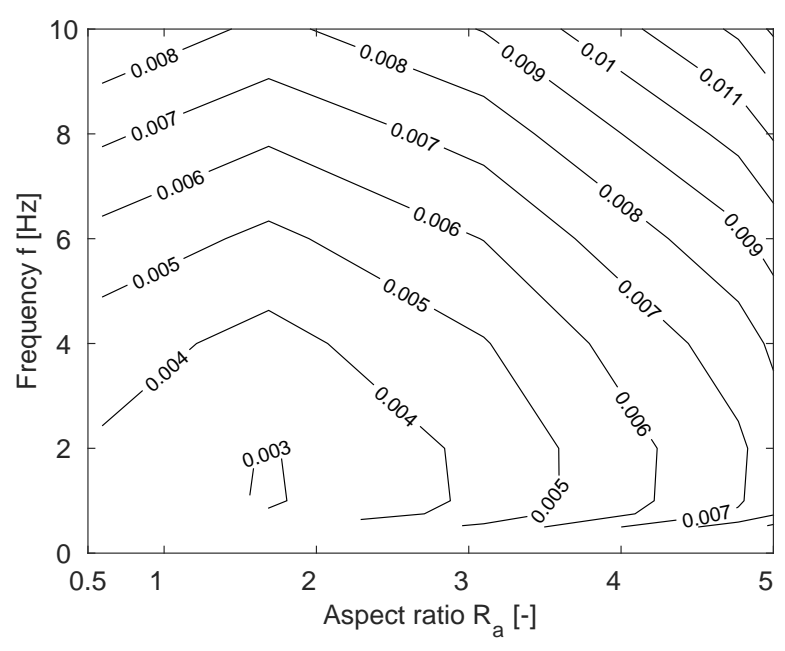

(a) Total entropy production rate consisted by three parts $\dot{S}_{p, t o t}$

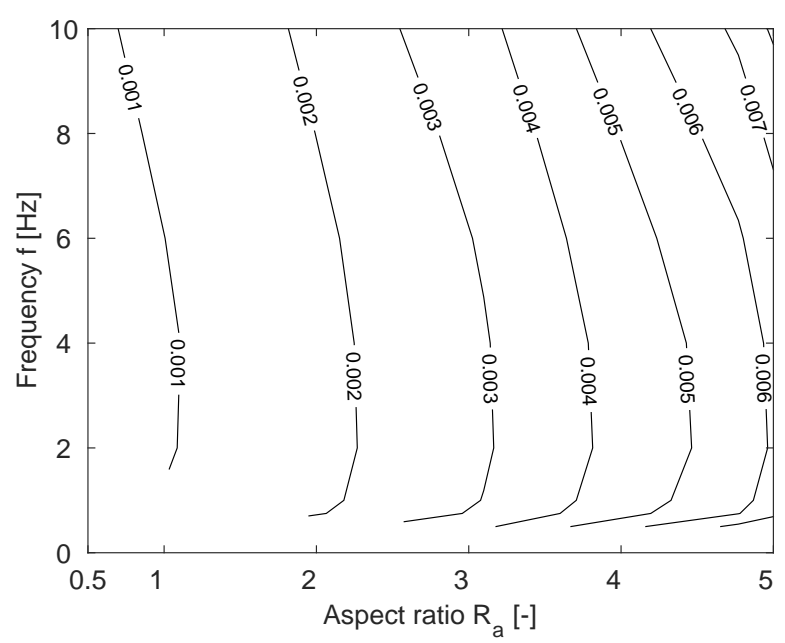

(c) Entropy production rate due to viscous dissipation $\dot{S}_{p, v d}$

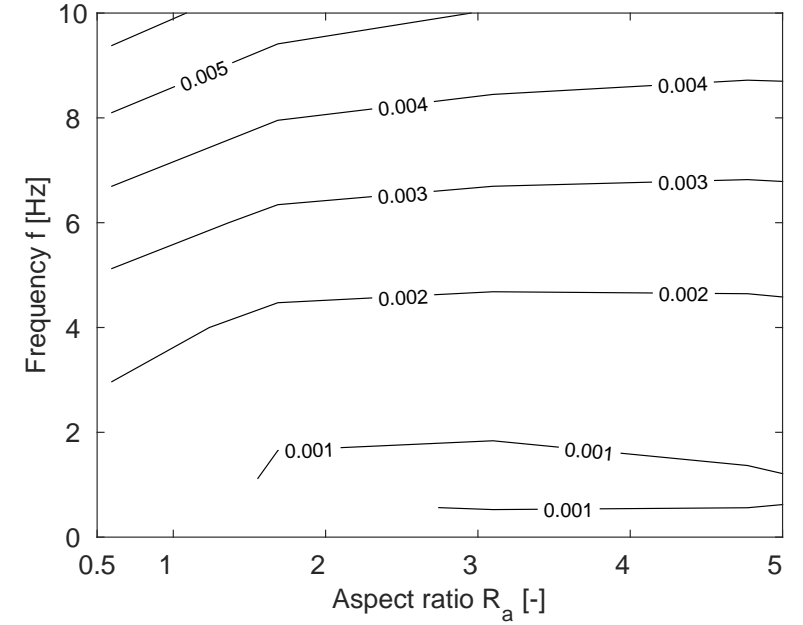

(b) Entropy production rate due to imperfect heat transfer $\dot{S}_{p, h t}$

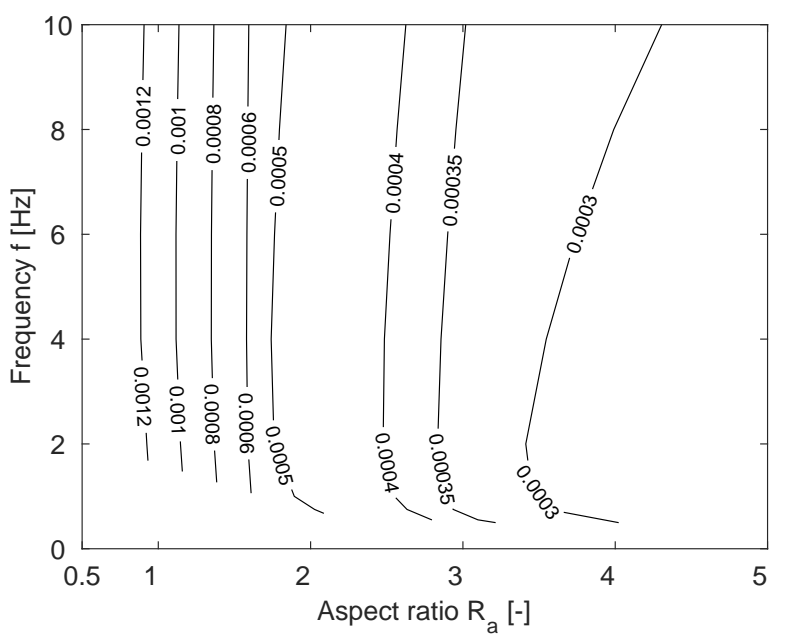

(d) Entropy production rate due to axial conduction $\dot{S}_{p, a c}$

Figure 7: Corresponding entropy production rate as a function of frequency $f$ and aspect ratio $R_{a}$ of AMRs using packed sphere bed with $D_{h}=0.100 \mathrm{~mm}$ (in the case of Figure $5 \mathrm{~b}$ ) 


\subsection{Parallel Plate Matrix}

Different from the packed sphere bed, the porosity of the parallel plate matrix can be adjusted by changing the plate thickness and flow channel height. Therefore we study three porosities $0.36,0.50$ and 0.64 , and present the results of optimum frequency and aspect ratio for different hydraulic diameters in Figure 8. The curve representing the porosity of 0.36 shows a similar pattern to that of the packed sphere bed. The optimum aspect ratio increases with the hydraulic diameter, while the optimum frequency decreases to the low point and then increases. The maximum COP is around 9.0, which is higher than the efficiency of the packed sphere bed, when the hydraulic diameter is $0.10 \mathrm{~mm}$, the frequency is $4.7 \mathrm{~Hz}$, and the aspect ratio is 2.1. It is found that higher frequency is preferable for the parallel plate matrix compared with the packed sphere bed.

In general, the maximum $\mathrm{COP}$ increases and the optimum frequency becomes smaller with the porosity, which can also be seen in some results from Ref. [15]. The highest COPs of regenerators using parallel plate matrix are 10.0 and 11.2 for the porosities of 0.50 and 0.64, respectively, corresponding to an optimum hydraulic diameter of $0.15 \mathrm{~mm}$. With the same hydraulic diameter, increased porosity will lead to a decrease in the plate thickness and solid mass, where a smaller mass flow rate is needed and this may make the COP higher with the same specific cooling power. However, the porosity could not be too high in a real design, because the power density per unit volume is decreased, which reversely requires a large magnet apparatus to realize the same cooling power.

The optimum hydraulic diameter for parallel plate matrix is around $0.10-0.15 \mathrm{~mm}$, and corresponding flow channel height ranges from 0.05 to $0.075 \mathrm{~mm}$. Besides, a uniform channel size in the parallel plate matrix is desired otherwise the mal-distribution flow may decrease the overall heat transfer coefficient and efficiency significantly [49]. Those requirements make the fabrication difficult and become the barriers for applying the parallel plate matrix in the real prototypes. 


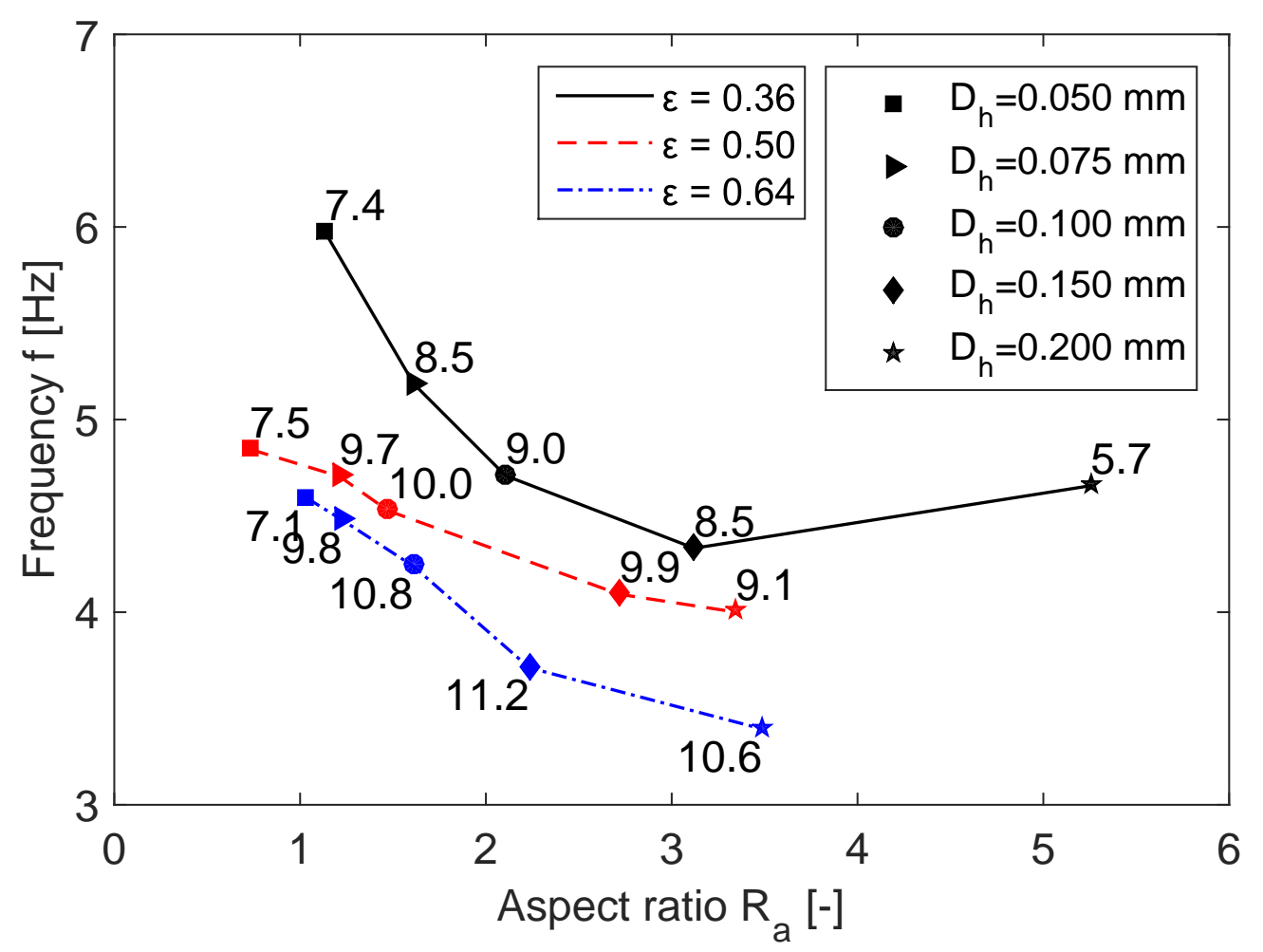

Figure 8: Optimum frequency $f$ and aspect ratio $R_{a}$ for regenerators using parallel plate matrix under different hydraulic diameters $D_{h}$ and porosities $\varepsilon$ 


\subsection{Micro-channel Matrix}

Since the circular and rectangular micro-channel matrices have similar characteristics, we only present the simulation results of the circular micro-channel matrix. Figure 9 shows the micro-channel matrix exhibits similar behavior as the parallel plate matrix. However, the best COP is smaller, which is 7.8, 9.0, and 10.1 for different porosities. This is expected since the micro-channel matrix provides slightly smaller $\mathrm{Nu} / f_{F}$ compared to the parallel plate matrix. At the same time, the optimum hydraulic diameter is 0.075 or $0.10 \mathrm{~mm}$, which is also the optimal diameter of the circular channels.

Like the parallel plate matrix, the problems of fabrication and long term durability also exist. A regenerator with monolithic perovskite structure fabricated by extrusion process has been tested [8] and the channel size was around $1 \mathrm{~mm}$, which was much larger than the optimum channel size in this study. It also revealed a problem of structure collapsing during sintering. Moore et al [9] used selective laser melting technology to fabricate a wavy-channel block and an array of fin-shaped rods. The minimum channel diameter was around 0.800 $\mathrm{mm}$ and a corrosion problem existed.

\subsection{Packed Screen Bed}

Compared with the packed sphere bed, the channels in the packed screen bed are more structured, giving an equivalent heat transfer performance but significantly lower pressure drop, as shown in Figure 3c. The torturous structure is capable of relieving the problem of the mal-distribution flow. Another advantage of the packed screen bed is relatively small axial conduction due to stacked structure, which is not discussed in detail here. Figure 10 shows the performance of AMRs using packed screen bed. It can be seen that the optimum frequency get close to that for the packed sphere bed, which is lower compared with the parallel plate and micro-channel matrices. With a porosity of 0.36 , the packed screen bed could provide the best COP around 7.8, which is higher than the packed sphere bed. At this point, the optimum frequency is $2.0 \mathrm{~Hz}$ and the aspect ratio is 3.3 . With increased 


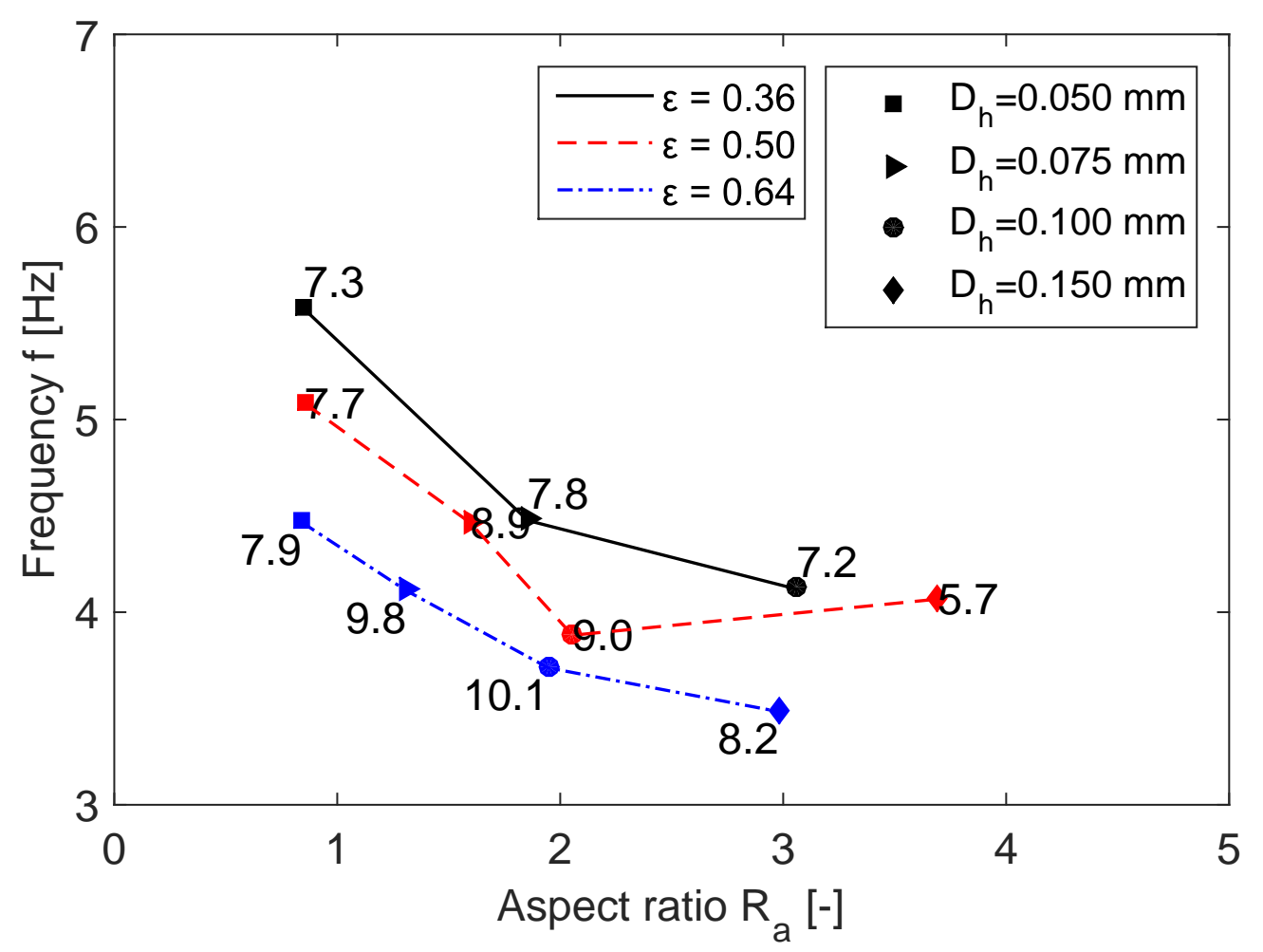

Figure 9: Optimum frequency $f$ and aspect ratio $R_{a}$ for regenerators using micro-channel matrix under different hydraulic diameters $D_{h}$ and porosities $\varepsilon$ 
porosity, the best COP increases considerably to 8.9 and 9.6 for the porosities of 0.50 and 0.64, respectively. Although it is difficult to fabricate the woven screens with existing MCM materials like $\mathrm{Gd}$ or ceramics, there is a probability of producing a similar geometry like packed felt bed in future. Table 4 summarizes the best COP of regenerators using different geometries and it is clearly seen that the other three geometries could provide higher efficiency at the optimum points compared with the packed sphere bed.

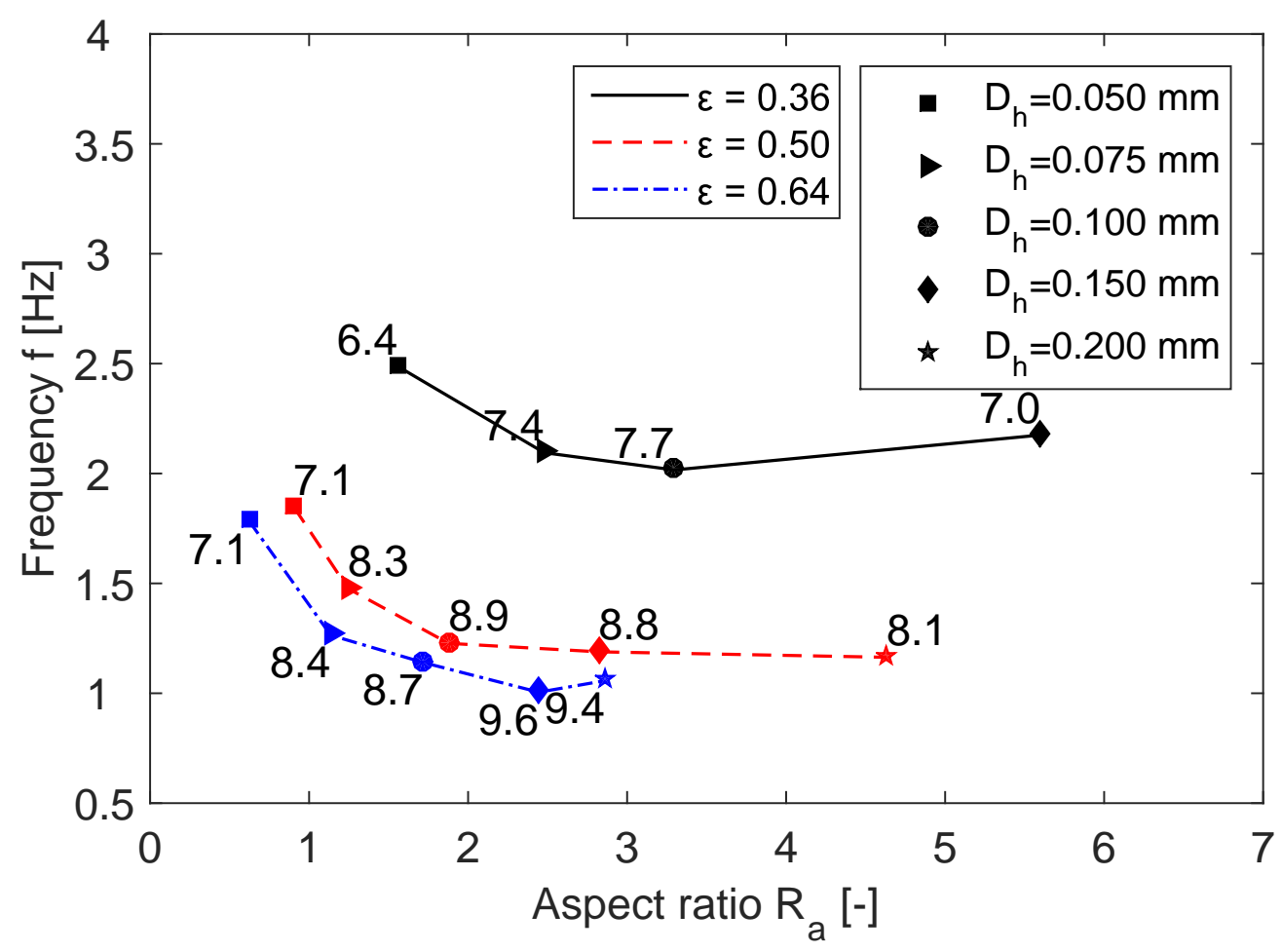

Figure 10: Optimum frequency $f$ and aspect ratio $R_{a}$ for regenerators using packed screen bed under different hydraulic diameters $D_{h}$ and porosities $\varepsilon$

\section{Conclusion}

We have presented a study on regenerator geometries for application in magnetocaloric refrigeration based on a 1D numerical model. A brief review of correlations of friction factor and heat transfer coefficient for different geometries is done. The results show that with a 
Table 4: Optimum parameters and best performance for different regenerator geometries

\begin{tabular}{llllll}
\hline \hline \multirow{2}{*}{ Geometry } & Porosity $\varepsilon$ & $\begin{array}{l}\text { Hydraulic di- } \\
\text { ameter } D_{h}\end{array}$ & $\begin{array}{l}\text { Aspect } \\
\text { tio } R_{a}\end{array}$ & ra- & Foquency $f$ \\
\hline Packed sphere bed & 0.36 & 0.075 & 1.0 & 2.3 & 7.60 \\
\hline Parallel plate matrix & 0.36 & 0.075 & 1.6 & 5.2 & 9.0 \\
& 0.50 & 0.10 & 1.5 & 4.5 & 10.0 \\
& 0.64 & 0.15 & 2.2 & 3.7 & 11.2 \\
\hline Micro-channel matrix & 0.36 & 0.05 & 1.9 & 4.5 & 7.8 \\
& 0.50 & 0.075 & 2.1 & 3.8 & 9.0 \\
& 0.64 & 0.10 & 2.0 & 3.7 & 10.1 \\
\hline Packed screen bed & 0.36 & 0.10 & 3.3 & 2.0 & 7.7 \\
& 0.50 & 0.15 & 1.9 & 1.2 & 8.9 \\
& 0.64 & 0.15 & 1.7 & 1.2 & 9.6 \\
\hline \hline
\end{tabular}

specific cooling power of $100 \mathrm{~W} / \mathrm{kg}$ MCM, the maximum COP of regenerators using packed sphere bed varies with the with the hydraulic diameter, and optimum frequency decreases and optimum aspect ratio increases. For a small hydraulic diameter as $0.50 \mathrm{~mm}$, the COP changes significantly with the aspect ratio while it is less sensitive to the frequency. In contrast, the COP becomes more sensitive to the frequency when the hydraulic diameter is equal to or larger than $0.15 \mathrm{~mm}$. For the packed sphere bed, the best COP is 7.6 when the hydraulic diameter, frequency, and aspect ratio is $0.075 \mathrm{~mm}, 2.3 \mathrm{~Hz}$, and 1.0 , respectively. The entropy production rates due to three main loss mechanisms, imperfect heat transfer, viscous dissipation, and axial conduction, as well as the total entropy production rates, are calculated and compared. It shows the imperfect heat transfer is more sensitive to the frequency and the viscous dissipation is affected much by the aspect ratio. And the conduction loss becomes significant when the aspect ratio is less than 1.0. It can be also seen that the minimum total entropy production rate fits the maximum COP concurrently.

In general, the parallel plate matrix, micro-channel matrix, and packed screen bed show better performance than the packed sphere bed. With a constant porosity, the optimum aspect ratio increases with the hydraulic diameter and the optimum frequency decreases in most cases. Higher porosity may lead to an increase in the maximum COP increases and the 
optimum frequency becomes smaller. Although the regenerators using parallel plate matrix and the micro-channel matrix could provide higher theoretical efficiency compared with the packed sphere bed, the fabrication of small channel size and the effect of mal-distribution flow may become barriers to the real application. In contrast, the packed screen bed or similar matrix structure could be a promising geometry.

\section{Acknowledgement}

This work was financed by the ENOVHEAT project which is funded by Innovation Fund Denmark (contract no 12-132673).

\section{References}

[1] K. A. Gschneidner Jr. and V. K. Pecharsky, "Thirty years of near room temperature magnetic cooling: Where we are today and future prospects," Int. J. Refrig., vol. 31, pp. 945-961, 2008.

[2] B. Yu, M. Liu, P. W. Egolf., and A. Kitanovski, "A review of magnetic refrigerator and heat pump prototypes built before the year 2010," Int. J. Refrig., vol. 33, pp. 1029-1060, 2010.

[3] A. Kitanovski, J. Tusekb, and A. Poredosc, Magnetocaloric Energy Conversion. Springer, 2015.

[4] T. Okamura, R. Rachi, N. Hirano, and S. Nagaya, "Improvement of 100w class room temperature magnetic refrigerator," Proceedings of the $2^{\text {nd }}$ International Conference of Magnetic Refrigeration at Room Temperature, Portoroz, Slovenia, pp. 377-382, 2007.

[5] K. Engelbrecht, D. Eriksen, C. R. H. Bahl, R. Bjørk, J. Geyti, J. A. Lozano, K. K. Nielsen, F. Saxild, A. Smith, and N. Pryds, "Experimental results for a novel rotary 
active magnetic regenerator," International Journal of Refrigeration, vol. 35, pp. 14981505, Sep 2012.

[6] D. Arnold, A. Tura, A. Ruebsaat-Trott, and A. Rowe, "Design improvements of a permanent magnet active magnetic refrigerator," International Journal of Refrigeration, vol. 37, pp. 99-105, 2014.

[7] S. Jacobs, J. Auringer, A. Boeder, J. Chell, L. Komorowski, J. Leonard, S. Russek, and C. Zimm, "The performance of a large-scale rotary magnetic refrigerator," International Journal of Refrigeration, vol. 37, pp. 84-91, Jan 2014.

[8] N. Pryds, F. Clemens, M. Menon, P. H. Nielsen, K. Brodersen, R. Bjrk, C. R. Bahl, K. Engelbrecht, K. K. Nielsen, and A. Smith, "A monolithic perovskite structure for use as a magnetic regenerator," Journal of the American Ceramic Society, vol. 94, no. 8, pp. 2549-2555, 2011.

[9] J. Moore, D. Klemm, D. Lindackers, S. Grasemann, R. Trger, J. Eckert, L. Lber, S. Scudino, M. Katter, and A. Barcza, "Selective laser melting of la (fe, co, si) 13 geometries for magnetic refrigeration," Journal of Applied Physics, vol. 114, no. 4, p. 043907, 2013.

[10] R. Radebaugh and B. Louie, "A simple, first step to the optimization of regenerator geometry," in In its Proc. of the 3rd Cryocooler Conf. p 177-198 (SEE N86-11367 0231), vol. 1, pp. 177-198, 1985.

[11] J. A. Barclay and S. Sarangi, "Selection of regenerator geometry for magnetic refrigerator applications," tech. rep., Los Alamos National Lab., NM (USA), 1984.

[12] P. Li, M. Gong, and J. Wu, "Geometric optimization of an active magnetic regenerative refrigerator via second-law analysis," Journal of Applied Physics, vol. 104, no. 10, p. 103536, 2008. 
[13] D. Vuarnoz and T. Kawanami, "Numerical analysis of a reciprocating active magnetic regenerator made of gadolinium wires," Applied Thermal Engineering, vol. 37, pp. 388395, 2012.

[14] J. Li, T. Numazawa, K. Mastumoto, Y. Yanagisawa, and H. Nakagome, "A modeling study on the geometry of active magnetic regenerator," in ADVANCES IN CRYOGENIC ENGINEERING: Transactions of the Cryogenic Engineering Conference-CEC, Volume 57, vol. 1434, pp. 327-334, AIP Publishing, 2012.

[15] J. Tušek, A. Kitanovski, and A. Poredo, "Geometrical optimization of packed-bed and parallel-plate active magnetic regenerators," International Journal of Refrigeration, vol. 36, no. 5, pp. 1456 - 1464, 2013.

[16] R. F. Benenati and C. B. Brosilow, "Void fraction distribution in beds of spheres," AIChE J., vol. 8, no. 3, pp. 359-361, 1962.

[17] R. F. Barron, G. Nellis, and J. M. Pfotenhauer, Cryogenic heat transfer. CRC Press, 1999.

[18] J. C. Armour and J. N. Cannon, "Fluid flow through woven screens," AIChE Journal, vol. 14, no. 3, pp. 415-420, 1968.

[19] K. K. Nielsen, G. Nellis, and S. Klein, "Numerical modeling of the impact of regenerator housing on the determination of nusselt numbers," International Journal of Heat and Mass Transfer, vol. 65, pp. 552-560, 2013.

[20] S. Ergun and A. A. Orning, "Fluid flow through randomly packed columns and fluidized beds," Industrial \& Engineering Chemistry, vol. 41, no. 6, pp. 1179-1184, 1949.

[21] M. Kaviany, Principles of heat transfer in porous media. Springer-Verlag, 1991. 
[22] L. Gibilaro, R. Di Felice, S. Waldram, and P. Foscolo, "Generalized friction factor and drag coefficient correlations for fluid-particle interactions," Chemical Engineering Science, vol. 40, no. 10, pp. 1817-1823, 1985.

[23] W. Kays and A. London, Compact Heat Exchangers, 3rd. Malabar, Florida: Krieger Publishing Company. 335p, 1984.

[24] N. Wakao, S. Kaguei, and T. Funazkri, "Effect of fluid dispersion coefficients on particleto-fluid heat transfer coefficients in packed beds: correlation of nusselt numbers," Chemical engineering science, vol. 34, no. 3, pp. 325-336, 1979.

[25] K. Engelbrecht, A Numerical Model of an Active Magnetic Regenerator Refrigerator with Experimental Validation. PhD thesis, University of Wisconsin - Madison, 2008.

[26] A. Bejan, Entropy generation minimization: the method of thermodynamic optimization of finite-size systems and finite-time processes. CRC press, 1995.

[27] R. K. Shah and A. L. London, Laminar flow forced convection in ducts: a source book for compact heat exchanger analytical data, vol. 1. Academic press, 1978.

[28] M. Nickolay and H. Martin, "Improved approximation for the nusselt number for hydrodynamically developed laminar flow between parallel plates," International journal of heat and mass transfer, vol. 45, no. 15, pp. 3263-3266, 2002.

[29] W. M. Kays, M. E. Crawford, and B. Weigand, Convective heat and mass transfer. Tata McGraw-Hill Education, 2012.

[30] K. K. Nielsen, Numerical modeling and analysis of the active magnetic regenerator. PhD thesis, Technical University of DenmarkDanmarks Tekniske Universitet, Department of PhysicsInstitut for Fysik, 2010. 
[31] M. Asadi, G. Xie, and B. Sunden, "A review of heat transfer and pressure drop characteristics of single and two-phase microchannels," International Journal of Heat and Mass Transfer, vol. 79, pp. 34-53, 2014.

[32] K. V. Sharp and R. J. Adrian, "Transition from laminar to turbulent flow in liquid filled microtubes," Experiments in fluids, vol. 36, no. 5, pp. 741-747, 2004.

[33] P. Wibulswas, Laminar-flow heat-transfer in non-circular ducts. PhD thesis, University of London, 1966.

[34] H. Hausen, M. Sayer, and A. J. Willmott, Heat Transfer in Counterflow, Parallel Flow and Cross Flow. McGraw-Hill New York, 1983.

[35] P.-S. Lee, S. V. Garimella, and D. Liu, "Investigation of heat transfer in rectangular microchannels," International Journal of Heat and Mass Transfer, vol. 48, no. 9, pp. 1688-1704, 2005.

[36] J. Sodre and J. Parise, "Friction factor determination for flow through finite wire-mesh woven-screen matrices," Journal of fluids engineering, vol. 119, no. 4, pp. 847-851, 1997.

[37] M. Tanaka, I. Yamashita, and F. Chisaka, "Flow and heat transfer characteristics of the stirling engine regenerator in an oscillating flow," JSME international journal. Ser. 2, Fluids engineering, heat transfer, power, combustion, thermophysical properties, vol. 33, no. 2, pp. 283-289, 1990.

[38] D. Gedeon and J. Wood, "Oscillating-flow regenerator test rig: Hardware and theory with derived correlations for screens and felts," tech. rep., NASA, USA, 1996.

[39] J.-W. Park, D. Ruch, and R. Wirtz, "Thermal/fluid characteristics of isotropic plainweave screen laminates as heat exchange surfaces," AIAA paper, vol. 208, p. 2002, 2002.

[40] S. Isshiki, A. Sakano, I. Ushiyama, and N. Isshiki, "Studies on flow resistance and heat transfer of regenerator wire meshes of stirling engine in oscillatory flow," JSME 
international journal. Series B, fluids and thermal engineering, vol. 40, no. 2, pp. 281289, 1997.

[41] Z.-C. Chang and P.-H. Chen, "Flow channeling effect on a regenerator's thermal performance," Cryogenics, vol. 38, no. 2, pp. 191-196, 1998.

[42] K. Hamaguchi, S. Takahashi, and H. Miyabe, "Thermal performance of regenerator matrix," Transactions of the Japanese Society of Mechanical Engineers, vol. 49, no. 445, pp. 2001-2010, 1983.

[43] G. Hadley, "Thermal conductivity of packed metal powders," International Journal of Heat and Mass Transfer, vol. 29, no. 6, pp. 909 - 920, 1986.

[44] U. Kurzweg and M. Jaeger, "Thermal pulse propagation and dispersion in laminar flow within conduits of finite wall conductivity," International journal of heat and mass transfer, vol. 40, no. 6, pp. 1391-1400, 1997.

[45] W. S. Chang, "Porosity and effective thermal conductivity of wire screens," Journal of heat transfer, vol. 112, no. 1, pp. 5-9, 1990.

[46] K. Engelbrecht, K. K. Nielsen, C. R. H. Bahl, C. P. Carroll, and D. van Asten, "Material properties and modeling characteristics for mnfep1-xasx materials for application in magnetic refrigeration," Journal of Applied Physics, vol. 113, no. 17, p. 173510, 2013.

[47] T. Lei, K. K. Nielsen, K. Engelbrecht, C. R. H. Bahl, H. Neves Bez, and C. T. Veje, "Sensitivity study of multi-layer active magnetic regenerators using first order magnetocaloric material la(fe,mn,si)13hy," Journal of Applied Physics, vol. 118, no. 1, p. 014903, 2015.

[48] R. Bjørk, C. R. H. Bahl, and M. Katter, "Magnetocaloric properties of $\mathrm{LaFe}_{13-x-y} \mathrm{Co}_{x} \mathrm{Si}_{y}$ and commercial grade Gd," Journal of Magnetism and Magnetic Materials, vol. 322, pp. 3882-3888, Dec 2010. 
[49] K. K. Nielsen, K. Engelbrecht, and C. R. Bahl, "The influence of flow maldistribution on the performance of inhomogeneous parallel plate heat exchangers," International Journal of Heat and Mass Transfer, vol. 60, pp. 432-439, 2013. 